\section{Vitrectomy with subretinal tissue plasminogen activator and ranibizumab for submacular haemorrhages secondary to age-related macular degeneration: retrospective case series of 45 consecutive}

\section{cases}

JJ González-López, G McGowan, E Chapman and D Yorston
$(P=0.012)$ and prompt surgery $(P=0.008)$ had better final visual acuities. A haemorrhage area of $\leq 30 \mathrm{~mm}^{2}$ had $91.3 \%$ sensitivity and $73.3 \%$ specificity for predicting a final visual acuity $\geq 6 / 60$.

Conclusion Small-gauge vitrectomy with subretinal rtPA and ranibizumab is effective for improving visual acuity in patients with submacular haemorrhages secondary to nAMD. Small haemorrhage area and prompt surgery are associated with better final visual acuity. Eye (2016) 30, 929-935; doi:10.1038/eye.2016.65; published online 8 April 2016

\section{Introduction}

Large subretinal haemorrhages (SMHs) are a recognised complication of neovascular agerelated macular degeneration (nAMD). The prognosis for untreated SMH is known to be poor. ${ }^{1,2}$ The subretinal blood is a barrier to diffusion of oxygen from the choroid; contraction of the blood clot damages the photoreceptors; and the iron in the haemoglobin is toxic. ${ }^{3}$ Bennett et $a l^{4}$ found that patients with submacular haemorrhage associated with AMD involving the fovea had a mean visual acuity of 20/1700 at final follow-up. A number of interventions have been proposed, including intravitreal anti-VEGF alone, ${ }^{5,6}$ intravitreal
Tennent Institute of Ophthalmology, NHS Greater Glasgow and Clyde, Glasgow, UK

Correspondence:

JJ González-López, Tennent Institute of Ophthalmology, Gartnavel General Hospital, 1053 Great Western Road, Glasgow G12 OYN, UK Tel: +44 (0)141 211 1041; Fax: +44 (0)1412112054. E-mail: juliojose.gonzalez@ live.com

Received: 22 August 2015 Accepted in revised form: 11 February 2016 Published online: 8 April 2016 
anti-VEGF combined with intravitreal gas and/or recombinant tissue plasminogen activator ( $\mathrm{rtPA}), 7,8$ and vitrectomy with subretinal rtPA and anti-VEGF.9,10 One retrospective comparative case series suggested that subretinal rtPA was more effective than intravitreal rtPA. ${ }^{11}$ Some trials of anti-VEGF agents specifically excluded eyes with large haemorrhages. ${ }^{12}$ Published case series of interventions to treat submacular haemorrhages often have fewer than 20 cases, and the end points are variable, including displacement of haemorrhage, change in visual acuity, or final vision. ${ }^{13}$

In addition, it is not yet clear what risk factors at presentation may affect final outcome. It is likely that the size, and thickness, of the haemorrhage will affect the probability of visual recovery; ${ }^{14}$ however, the thickness of the haemorrhage may be difficult to measure accurately with optical coherence tomography (OCT), as a dense haemorrhage may obscure the signal from the retinal pigment epithelium. The haemorrhage area may be a more reproducible measurement that could help to identify the eyes that are most likely to benefit from treatment.

Since 2011, the vitreoretinal service at Gartnavel General Hospital has offered vitrectomy with subretinal rtPA and gas to any patient with a recent-onset, large (>10 disc areas), submacular haemorrhage secondary to nAMD. The main objective of this study is to assess the efficacy of small-gauge vitrectomy with subretinal rtPA and ranibizumab for submacular haemorrhages secondary to nAMD. A secondary objective was to identify the factors associated with a better outcome.

\section{Materials and methods}

A retrospective case series analysis was performed. All patients treated with 23-gauge pars plana vitrectomy with subretinal rtPA and ranibizumab for large ( $>10$ disc areas) submacular haemorrhages involving the fovea secondary to nAMD between March 2011 and January 2015 were included in the study. Patients with a SMH whose aetiology was a disease other than nAMD and those presenting more than 14 days from the onset of visual acuity were excluded from the study. All research adhered to the tenets of the Declaration of Helsinki. All patients included signed a written informed consent form for their surgical intervention.

Preoperative and postoperative examinations consisted of Snellen best corrected visual acuity measurement (BCVA), colour fundus photography, macular optical coherence tomography (Topcon OCT-2000, Topcon Corporation, Tokyo, Japan), anterior segment examination, Goldmann tonometry, and dilated funduscopy. Haemorrhage area and thickness (distance between retinal pigment epithelium and inner limiting
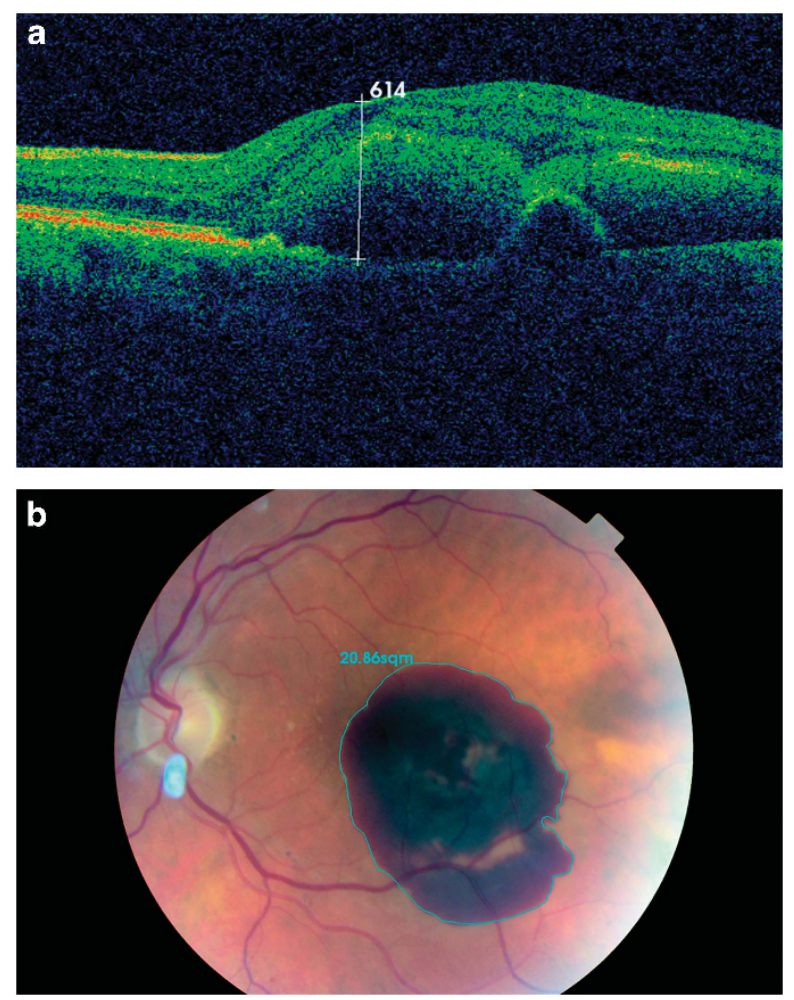

Figure 1 (a) Macular optical coherence tomography centred in the fovea of a patient with a recent-onset submacular haemorrhage, showing the method used for calculating the submacular haemorrhage thickness. Distance was calculated using the calliper function of Topcon OCT-2000, drawing a line between the inner limiting membrane and the nearest point of the retinal pigment epithelium. (b) Colour fundus photograph of the same patient, showing the method used for calculating the submacular haemorrhage area. Area was calculated using the area function of Topcon OCT-2000 software, by drawing the area of the haemorrhage.

membrane) were calculated using the Topcon OCT-2000 software (Figure 1). Unlike haemorrhage area measurements, which were found to be accurate, thickness measurements were unreliable because of the difficulty in identifying the retinal pigment epithelium in very thick haemorrhages. In contrast, haemorrhage area was easy to calculate, as the edge of the haemorrhage was clearly defined. Thus, only haemorrhage area data were used for further analysis. Angiography was not routinely performed because of the difficulty of identifying a choroidal neovascular lesion under a submacular haemorrhage.

The following surgical technique was employed: a complete 23G pars plana vitrectomy was performed (Constellation Vision System, Alcon, Fort Worth, TX, USA), with induction of a posterior vitreous detachment if necessary. We used a $23 \mathrm{G}$ cannula with a retractable 41G tip (Dutch Ophthalmic Research Center (DORC), 
Zuidland, The Netherlands), connected by tubing to a tuberculin syringe containing $\sim 0.5-0.7 \mathrm{ml}$ of $\mathrm{rtPA}$ $125 \mu \mathrm{g} / \mathrm{ml}$ and $0.06 \mathrm{ml}$ of Ranibizumab $10 \mathrm{mg} / \mathrm{ml}$, using the technique previously described by Treumer, Hillenkamp, and colleagues. ${ }^{9-11,15}$ The $41 G$ tip was inserted into the subretinal space, and the assistant slowly injected the contents of the syringe, creating a local retinal detachment encompassing the haemorrhage. The total volume infused varies from 0.5 to $0.75 \mathrm{ml}$ with larger volumes for larger haemorrhages. There is $\sim 0.15 \mathrm{ml}$ dead space in the subretinal injection cannula. At $125 \mu \mathrm{g} / \mathrm{ml}$ of $\mathrm{rtPA}, 0.5 \mathrm{ml}$ contains $\sim 60 \mu \mathrm{g}$ of rtPA. Fluid air exchange was incomplete-the eye was filled with air only to the level of the dome of detached retina. After ensuring a gas tight seal of the ports, the vitreous cavity was filled with a $25 \%$ sulphur hexafluoride gas/air mixture. Patients were instructed to maintain a supine position for $4 \mathrm{~h}$ after surgery, and then to sit up and lean forward overnight.

Patients were reviewed on days 1, 14, and 28 postoperatively, and on a monthly basis thereafter. Patients received two further monthly $0.05 \mathrm{ml}$ ranibizumab injections after surgery and were treated on a pro re nata regime after the third month. Criteria for reinjection were new haemorrhages, persistent or new subretinal fluid on OCT, or two-line drop in Snellen BCVA from the previous visit. Although NICE guidelines do not support ranibizumab use in patients with nAMD and visual acuity worse than 6/96, this treatment can be commissioned by NHS in Scotland if the treating ophthalmologist considers it to be beneficial for the patient.

\section{Statistics}

Qualitative variables were expressed as percentages. Quantitative variables were expressed as mean values \pm SD if they followed a normal distribution or as median values (range) if they did not. Snellen visual acuity was transformed to LogMAR for statistical analysis. $^{16}$

Differences between two related continuous variables were tested with the paired T-test, and between two independent variables with the independent samples T-tests, when normality and homoscedasticity conditions allowed it. When this was not possible, Wilcoxon or Mann-Whitney test were used, respectively. Correlation between two continuous variables was tested using Pearson's method. Multivariate analysis for bivariate dependent variables was performed with a logistic regression model, and for continuous dependent variables using a multiple linear regression model. The selection of variables in the final model was performed by a forwardconditional method, with significance levels of $\leq 0.05$ for inclusion and $\geq 0.1$ for exclusion, forcing age and gender into the equation. Collinearity was measured using Tolerance and Variance Inflation Factor.

Results were considered statistically significant when $P<0.05$. Data were analysed using IBM SPSS Statistics, version 20 (International Business Machine Corp., Endicott, NY, USA), and Stata/SE, version 12.0 (StataCorp, College Station, TX, USA).

\section{Results}

Forty-five patients were included in the study. Their characteristics are summarised in Table 1. Mean age was $77.07 \pm 9.67$ years, and 32 of 45 patients $(71.1 \%)$ were women. On average, patients presented to the clinic $6.89 \pm 5.75$ days after the onset of symptoms. Fourteen patients were pseudophakic in the study eye, and 13 $(28.9 \%)$ had received previous anti-VEGF treatment for wet AMD in the study eye. Only one patient had a visual acuity of $6 / 36$ or better on presentation. Three patients were taking warfarin $(6.7 \%), 18(40 \%)$ were on aspirin, and $3(6.7 \%)$ on clopidogrel.

Surgery was performed an average of $6.98 \pm 5.70$ days after the onset of symptoms, and patients were observed for a follow-up period of $12.9 \pm 10.8$ months. On average, patients received $3.36 \pm 2.36$ injections of anti-VEGF after the surgery. Postoperative complications were observed

Table 1 Presenting characteristics, treatment details, and postoperative complications of the 45 patients included in the study

\begin{tabular}{lc}
\hline Age (years) & $77.07 \pm 9.67$ \\
Gender (female) & $32(71.1 \%)$ \\
Previous wet AMD & $13(28.9 \%)$ \\
Number of injections & $6.5 \pm 6.16$ \\
Haemorrhage area $\left(\mathrm{mm}^{2}\right)$ & $40.64 \pm 20.20$ \\
Haemorrhage thickness $(\mu \mathrm{m})$ & $1211.95 \pm 444.20$ \\
$V A$ at presentation $($ LogMAR) & $1.85 \pm 0.49$ \\
$6 / 36$ & $1(2.2 \%)$ \\
$6 / 60$ & $8(17.8 \%)$ \\
$3 / 60$ & $1(2.2 \%)$ \\
$2 / 60$ & $2(4.4 \%)$ \\
$1 / 60$ & $2(4.4 \%)$ \\
Counting fingers & $14(31.1 \%)$ \\
Hand movement & $17(37.8 \%)$ \\
Pseudophakic & $14(31.1 \%)$ \\
Days between onset and presentation & $6.89 \pm 5.75$ \\
Days between onset and surgery & $6.98 \pm 5.70$ \\
Number of injections $(3$ monthly+prn) & $3.36 \pm 2.36$ \\
Follow-up period (months) & $12.9 \pm 10.8$ \\
Any complication & $22(48.9 \%)$ \\
Repeated submacular bleeding & $13(28.9 \%)$ \\
Cataract & $4(8.9 \%)$ \\
Vitreous bleeding & $2(4.4 \%)$ \\
Retinal detachment & $1(2.2 \%)$ \\
RPE rip & $1(2.2 \%)$ \\
Macular hole & $1(2.2 \%)$ \\
\hline & \\
\hline &
\end{tabular}


in 22 patients $(48.9 \%)$. The most frequent complications were recurrent submacular bleeding (13 patients, $28.9 \%$ ), cataracts requiring phacoemulsification surgery $(4$ patients; $8.9 \%$ ), and vitreous bleeding (2 patients; $4.4 \%$ ). Retinal detachment, RPE rip, and full thickness macular hole were observed in one patient each (2.2\%). No differences in final visual acuity were observed between patients presenting and not presenting postoperative complications $(P=0.451)$. No systemic complications were observed in any of the patients included in the study.

We did not observe any significant relationship between any of the individual antiplatelet or anticoagulant agents and risk of rebleed (warfarin $P>0.999$; aspirin $P=0.130$; clopidogrel $P=0.169$ ). We observed a nonstatistically significant trend when we compared the use of any antiplatelet agent (aspirin or clopidogrel or both) with the risk of rebleed $(P=0.096$; $\mathrm{OR}=3.5$; 95 confidence interval (CI) 0.87-14.11).

However, this was not found to be a significant predictor of final visual result in any of the multivariate models.

Figure 2a shows the change in visual acuity between presentation and last follow-up. On average, visual acuity improved $-0.59 \pm 0.61$ LogMAR between presentation and last follow-up $(P<0.001)$. Visual acuity improved in 33 patients $(73.3 \%)$, remained unchanged in 10 patients $(22.2 \%)$, and worsened in 2 patients $(4.4 \%)$.

Univariate analysis did not find any statistically significant relation between final BCVA and gender $(P=0.813)$, age $(P=0.385)$, days between onset and surgery $(P=0.145)$, previous anti-VEGF treatment $(P=0.264)$, antiplatelet $(P=0.742)$ or anticoagulant treatment $(P=0.803)$, or follow-up period $(P=0.484)$. The only significant predictors observed in bivariate analysis were subretinal haemorrhage area $(P=0.001)$ and presenting LogMAR BCVA $(P=0.005)$. Predictors of final visual acuity were further analysed using a multiple linear regression model (Table 2, model A). This confirmed that patients with smaller haemorrhages $(P=0.012)$ and shorter times between onset of symptoms and surgery $(P=0.008)$ had better final visual acuities, independently of age, gender, presenting BCVA, or follow-up time. The model B in Table 2 shows the results of the binary logistic regression model analysing the factors associated with a final visual acuity $\geq 6 / 60$ (1.0 LogMAR). Only a smaller haemorrhage area at presentation showed a statistically significant association with a final visual acuity $\geq 6 / 60$.

ROC curve analysis showed that the macular haemorrhage area was the single best predictor of a final visual acuity $\geq 6 / 60$ (Figure $2 b$ ). Area under the ROC curve was 0.794 (95\% CI 0.625-0.964). A haemorrhage with an area of $30 \mathrm{~mm}^{2}$ had $91.3 \%$ sensitivity and $73.3 \%$ specificity for predicting a final visual acuity $\geq 6 / 60$.

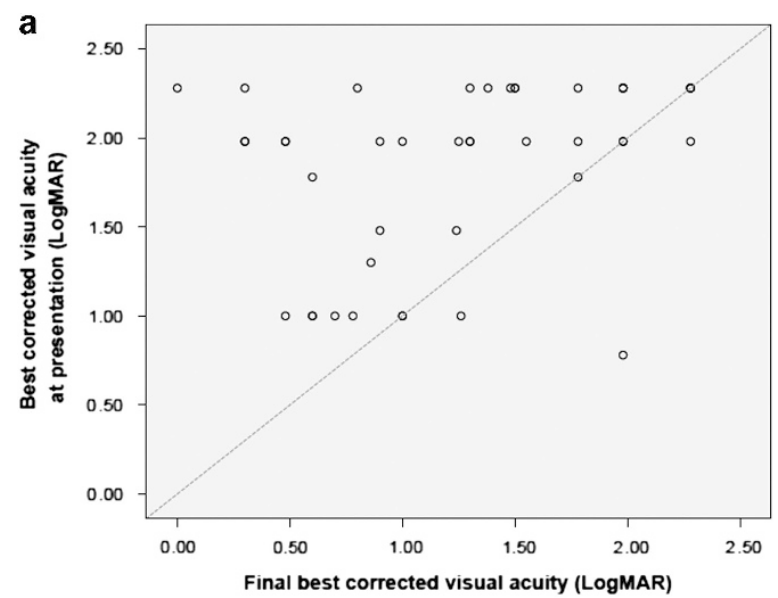

b

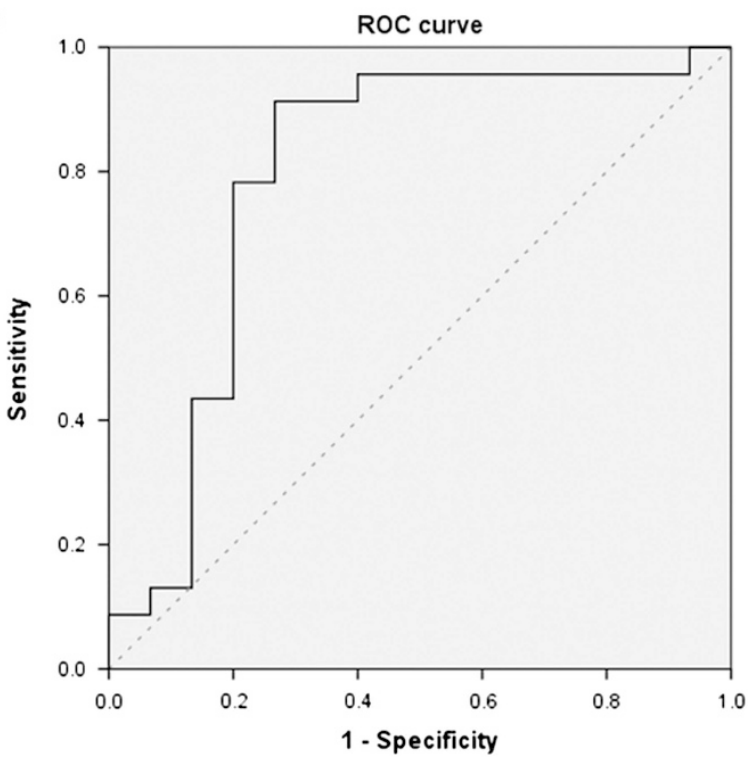

Figure 2 (a) Dot plot showing the change in LogMAR visual acuity between presentation and last follow-up in the 45 patients included in the study. (b) Receiver operating characteristic curve showing the relationship between sensitivity and 1-specificity of submacular haemorrhage area for the prediction of a final corrected visual acuity $\geq 6 / 60$ (area under curve $=0.794$; $95 \%$ confidence interval 0.625-0.964).

Finally, Table 3 shows final BCVA results by tertiles of time between onset of symptoms and surgery, BCVA at presentation, and subretinal haemorrhage area.

\section{Discussion}

The main findings of this study are:

- Visual acuity improved in 33 of 45 patients.

- Postoperative complications occurred in 22 of 45 patients.

- Patients with smaller haemorrhages and shorter surgical delays obtained better final visual results. 
Table 2 Model A: multiple linear regression analysis of factors associated with final LogMAR VA; $R^{2}=0.389$. Model B: binary logistic regression analysis of factors associated with a final VA $>6 / 60(1 \operatorname{LogMAR}) ; R^{2}$ Nagelkerke $=0.429$

\begin{tabular}{|c|c|c|c|c|c|c|}
\hline Model A & $\beta$ & SE of $\beta$ & Standardised $\beta$ & $\mathrm{P}$ & Tolerance & $\begin{array}{c}\text { Variance } \\
\text { inflation factor }\end{array}$ \\
\hline Age in years & 0.007 & 0.011 & 0.090 & 0.535 & 0.953 & 1.049 \\
\hline Gender (female) & 0.277 & 0.219 & 0.190 & 0.216 & 0.867 & 1.153 \\
\hline Haemorrhage area $\left(\mathrm{mm}^{2}\right)$ & 0.014 & 0.005 & 0.431 & 0.012 & 0.757 & 1.322 \\
\hline Days between onset and surgery & 0.063 & 0.022 & 0.425 & 0.008 & 0.887 & 1.128 \\
\hline Presenting VA (LogMAR) & 0.183 & 0.220 & 0.138 & 0.413 & 0.713 & 1.402 \\
\hline Months of follow-up & -0.004 & 0.009 & -0.063 & 0.675 & 0.903 & 1.108 \\
\hline Constant & -0.713 & 0.948 & & 0.458 & & \\
\hline Model B & $\beta$ & SE of $\beta$ & $\begin{array}{l}\text { OR }\left(e^{\beta}\right) \text { and } 95 \% \\
\text { confidence interval }\end{array}$ & $\mathrm{P}$ & Tolerance & $\begin{array}{c}\text { Variance } \\
\text { inflation factor }\end{array}$ \\
\hline Gender (female) & -1.936 & 1.114 & $0.144(0.016-1.28)$ & 0.082 & 0.911 & 1.097 \\
\hline Haemorrhage area $\left(\mathrm{mm}^{2}\right)$ & -0.063 & 0.030 & $0.939(0.885-0.996)$ & 0.039 & 0.801 & 1.248 \\
\hline Presenting VA (LogMAR) & -1.809 & 0.939 & $0.164(0.026-1.03)$ & 0.054 & 0.760 & 1.316 \\
\hline Constant & 6.610 & 2.571 & $742.70(4.809-114713)$ & 0.010 & & \\
\hline
\end{tabular}

Table 3 Final LogMAR visual acuity (VA) results by time between haemorrhage onset and surgery, VA at presentation, and haemorrhage area

\begin{tabular}{lrccc}
\hline & $\mathrm{N}$ & Final VA & VA change & $\mathrm{P}$ (Wilcoxon) \\
\hline $\begin{array}{l}\text { Number of days } \\
\quad 17\end{array}$ & & & & \\
$\quad 17$ & $1.17 \pm 0.60$ & $-0.67 \pm 0.61$ & 0.002 \\
$\quad>8$ & 13 & $1.25 \pm 0.65$ & $-0.52 \pm 0.57$ & 0.006 \\
& 15 & $1.44 \pm 0.72$ & $-0.56 \pm 0.70$ & 0.026 \\
VA at presentation & & & & \\
$\quad 1 / 60$ & 14 & $0.98 \pm 0.45$ & $-0.28 \pm 0.35$ & 0.091 \\
Counting fingers & 14 & $1.21 \pm 0.66$ & $-0.77 \pm 0.66$ & 0.004 \\
Hand motion & 17 & $1.59 \pm 0.69$ & $-0.69 \pm 0.69$ & 0.001 \\
& & & & \\
Haemorrhage area & & & & \\
$\quad 1428 \mathrm{~mm}^{2}$ & 14 & $0.82 \pm 0.43$ & $-0.84 \pm 0.60$ & 0.001 \\
$28-48 \mathrm{~mm}^{2}$ & 17 & $1.37 \pm 0.58$ & $-0.50 \pm 0.57$ & 0.012 \\
$>48 \mathrm{~mm}^{2}$ & 14 & $1.65 \pm 0.68$ & $-0.46 \pm 0.66$ & 0.021 \\
\hline
\end{tabular}

Successful improvement of visual acuity in submacular haemorrhages secondary to nAMD has been previously reported using intravitreal gas; intravitreal gas and rtPA; intravitreal gas, rtPA, and bevacizumab; ${ }^{17}$ vitrectomy with intravitreal gas and subretinal rtPA; $11,18,19$ and vitrectomy with intravitreal gas and subretinal rtPA and anti-VEGF. ${ }^{9,10}$ A recent review by Stanescu-Segall et al ${ }^{20}$ summarises the findings of these previous studies. To date, there is no consensus on the optimal management for patients presenting with this severe complication of nAMD.

Unsurprisingly, our results suggest that patients tend to benefit more from this intervention when the area of the haemorrhage is small, and if surgery is conducted promptly. To the best of our knowledge, this is the first study that analyses the effect of haemorrhage area on final visual acuity. As expected, we have observed that smaller haemorrhages correlate with better final visual acuities. In eyes with haemorrhages $>48 \mathrm{~mm}^{2}$, both final visual acuity and BCVA improvement were smaller than in patients with less extensive haemorrhages. We recommend that in this subgroup of patients, surgery should be reserved for those who have already lost vision in their contralateral eye.

In addition, we found better results in patients who underwent surgery promptly after the onset of symptoms. In spite of this, we have observed improvement in visual acuity even in patients who underwent surgery between 8 and 14 days after the onset of symptoms.

Subgroup analysis failed to show a statistically significant change in visual acuity in patients with presenting BCVA of $\geq 1 / 60$. This could be because of the limited statistical power of our study in order to detect smaller visual acuity gains. Prospective studies with larger sample size would help to determine the benefit of this intervention in these patients.

The rate and distribution of complications is similar to previous reports. ${ }^{10}$ Random effect meta-analysis showed that the incidence of RPE rips, macular hole, and retinal detachments is $\sim 2.3 \%$ (95 CI $0-5.5 \%$ ) for each of these complications in this procedure.

We hypothesise that the immediate benefit of this technique is due to the displacement of the haemorrhage. However, if the CNVs are not treated at the same time with anti-VEGF, any visual improvement is likely to be short-lived. Although ranibizumab is diluted by the rtPA, this dilution is much less than the conventional 
route of administration in which it is diluted by $\sim 5 \mathrm{ml}$ of vitreous.

Our study has several limitations. First, we did not include a control group. It is possible that intravitreal antiVEGF injections alone could be effective for improving visual acuity in patients with submacular haemorrhages secondary to nAMD. However, a retrospective case series by Stifter $e t a l^{21}$ in similar patients showed improvement in visual acuity in only 10 of 21 eyes, no change in 2, and worsening in 9 of 21 treated with intravitreal bevacizumab only. Jain et $a^{22}$ treated 14 eyes with submacular haemorrhages with intravitreal bevacizumab or ranibizumab, and showed improvement in 13 of 14 eyes. However, the haemorrhages in the included patients were significantly smaller $\left(25.1 \pm 24.3 \mathrm{~mm}^{2}\right)$, the patients presented earlier (median 4 days, range 1-7 days), and had better presenting visual acuities (median 20/400, range hand motion to 20/60) than those included in this study. The CATT study, a large, multicentre randomised clinical trial of ranibizumab vs bevacizumab, also included eyes with macular haemorrhages, but again these were patients with better prognosis, as eyes with visual acuities worse than $6 / 96$ were excluded. ${ }^{23}$ In a subgroup analysis of lesions composed $>50 \%$ of blood, they showed a 3 -line improvement at year 1 in $7.7 \%$ of patients, changes $<3$ lines in $60 \%$ of patients, and worsening of $>3$ lines in $32.1 \%$ of patients. ${ }^{5}$ Again, the eyes included in this study probably have a more favourable prognosis than our patients, as mean presenting visual acuity was $20 / 80$, and total retinal thickness was significantly smaller $(524 \mu \mathrm{m})$. Thus, it is possible that intravitreal anti-VEGF alone could also be effective in small haemorrhages with visual acuities better than counting fingers. Comparative studies are required in this subset of patients in order to determine the optimal treatment.

Second, in 4 of 31 phakic eyes, phacoemulsification was performed postoperatively because of cataract progression. However, the degree of lens opacity at presentation was mild in these patients. Thus, the contribution of cataract surgery to the overall improvement in BCVA was probably small.

Lastly, visual acuities were measured using the Snellen chart, and then transformed into LogMAR for statistical analysis. This conversion allows the use of parametric tests, and has been previously validated. ${ }^{16}$

In conclusion, this study shows that small-gauge vitrectomy with subretinal rtPA and ranibizumab is an effective therapy for improving visual acuity in patients with submacular haemorrhages secondary to nAMD. Small haemorrhage area and prompt surgery are associated with better final visual acuity.

\section{Summary}

What was known before

- Large subretinal haemorrhages are a recognised complication of neovascular age-related macular degeneration (nAMD).

- Their prognosis is poor, with a final visual acuity of 20/1700 if left untreated.

- A number of interventions have been proposed, including intravitreal anti-VEGF alone, intravitreal anti-VEGF combined with intravitreal gas and/or recombinant tissue plasminogen activator (rtPA), and vitrectomy with subretinal rtPA and anti-VEGF.

What this study adds

- Small-gauge vitrectomy with subretinal rtPA and ranibizumab is an effective therapy for improving visual acuity in patients with submacular haemorrhages secondary to nAMD.

- Postoperative complications occurred in 22 of 45 patients, although they did not influence the final visual result.

- Patients with smaller haemorrhages and shorter surgical delays presented better final visual results.

\section{Conflict of interest}

JJG-L has received study grants from Alcon, Allergan, MSD, Novartis, Santen, and Thèa, and is a consultant for Bayer. The other authors declare no conflict of interest.

\section{References}

1 Avery RL, Fekrat S, Hawkins BS, Bressler NM. Natural history of subfoveal subretinal hemorrhage in age-related macular degeneration. Retina 1996; 16(3): 183-189.

2 Bressler NM, Bressler SB, Childs AL, Haller JA, Hawkins BS, Lewis $\mathrm{H}$ et al. Surgery for hemorrhagic choroidal neovascular lesions of age-related macular degeneration: ophthalmic findings: SST report no. 13. Ophthalmology 2004; 111(11): 1993-2006.

3 Glatt H, Machemer R. Experimental subretinal hemorrhage in rabbits. Am J Ophthalmol 1982; 94(6): 762-773.

4 Bennett SR, Folk JC, Blodi CF, Klugman M. Factors prognostic of visual outcome in patients with subretinal hemorrhage. Am J Ophthalmol 1990; 109(1): 33-37.

5 Altaweel MM, Daniel E, Martin DF, Mittra RA, Grunwald JE, Lai MM et al. Outcomes of eyes with lesions composed of $>50 \%$ blood in the Comparison of Age-related Macular Degeneration Treatments Trials (CATT). Ophthalmology 2015; 122(2): 391-398 e395.

6 Kim JH, Chang YS, Kim JW, Kim CG, Yoo SJ, Cho HJ. Intravitreal anti-vascular endothelial growth factor for submacular hemorrhage from choroidal neovascularization. Ophthalmology 2014; 121(4): 926-935.

7 Mayer WJ, Hakim I, Haritoglou C, Gandorfer A, Ulbig M, Kampik A et al. Efficacy and safety of recombinant tissue plasminogen activator and gas versus bevacizumab and gas for subretinal haemorrhage. Acta Ophthalmol 2013; 91(3): 274-278.

8 Sacu S, Stifter E, Vecsei-Marlovits PV, Michels S, Schutze C, Prunte $C$ et al. Management of extensive subfoveal 
haemorrhage secondary to neovascular age-related macular degeneration. Eye 2009; 23(6): 1404-1410.

9 Treumer F, Klatt C, Roider J, Hillenkamp J. Subretinal coapplication of recombinant tissue plasminogen activator and bevacizumab for neovascular age-related macular degeneration with submacular haemorrhage. $\mathrm{Br} J$ Ophthalmol 2010; 94(1): 48-53.

10 Treumer F, Roider J, Hillenkamp J. Long-term outcome of subretinal coapplication of rtPA and bevacizumab followed by repeated intravitreal anti-VEGF injections for neovascular AMD with submacular haemorrhage. Br J Ophthalmol 2012; 96(5): 708-713.

11 Hillenkamp J, Surguch V, Framme C, Gabel VP, Sachs HG. Management of submacular hemorrhage with intravitreal versus subretinal injection of recombinant tissue plasminogen activator. Graefes Arch Clin Exp Ophthalmol 2010; 248(1): 5-11.

12 Chakravarthy U, Harding SP, Rogers CA, Downes SM, Lotery AJ, Culliford LA et al. Alternative treatments to inhibit VEGF in age-related choroidal neovascularisation: 2-year findings of the IVAN randomised controlled trial. Lancet 2013; 382(9900): 1258-1267.

13 van Zeeburg EJ, van Meurs JC. Literature review of recombinant tissue plasminogen activator used for recentonset submacular hemorrhage displacement in age-related macular degeneration. Ophthalmologica 2013; 229(1): 1-14.

14 Scupola A, Coscas G, Soubrane G, Balestrazzi E. Natural history of macular subretinal hemorrhage in age-related macular degeneration. Ophthalmologica 1999; 213(2): 97-102.

15 Klettner A, Groteluschen S, Treumer F, Roider J, Hillenkamp J. Compatibility of recombinant tissue plasminogen activator (rtPA) and aflibercept or ranibizumab coapplied for neovascular age-related macular degeneration with submacular haemorrhage. Br J Ophthalmol 2015; 99(6): 864-869.

16 Lange C, Feltgen N, Junker B, Schulze-Bonsel K, Bach M. Resolving the clinical acuity categories 'hand motion' and 'counting fingers' using the Freiburg Visual Acuity Test (FrACT). Graefes Arch Clin Exp Ophthalmol 2009; 247(1): 137-142.

17 Meyer CH, Scholl HP, Eter N, Helb HM, Holz FG. Combined treatment of acute subretinal haemorrhages with intravitreal recombined tissue plasminogen activator, expansile gas and bevacizumab: a retrospective pilot study. Acta Ophthalmol 2008; 86(5): 490-494.

18 Haupert CL, McCuen BW 2nd, Jaffe GJ, Steuer ER, Cox TA, Toth CA et al. Pars plana vitrectomy, subretinal injection of tissue plasminogen activator, and fluid-gas exchange for displacement of thick submacular hemorrhage in age-related macular degeneration. Am J Ophthalmol 2001; 131(2): 208-215.

19 Olivier S, Chow DR, Packo KH, MacCumber MW, Awh CC. Subretinal recombinant tissue plasminogen activator injection and pneumatic displacement of thick submacular hemorrhage in Age-Related macular degeneration. Ophthalmology 2004; 111(6): 1201-1208.

20 Stanescu-Segall D, Balta F, Jackson TL. Submacular hemorrhage in neovascular age-related macular degeneration: a synthesis of the literature. Surv Ophthalmol 2015; 61(1): 18-32.

21 Stifter E, Michels S, Prager F, Georgopoulos M, Polak K, Hirn $C$ et al. Intravitreal bevacizumab therapy for neovascular age-related macular degeneration with large submacular hemorrhage. Am J Ophthalmol 2007; 144(6): 886-892.

22 Jain S, Kishore K, Sharma YR. Intravitreal anti-VEGF monotherapy for thick submacular hemorrhage of less than 1 week duration secondary to neovascular age-related macular degeneration. Indian J Ophthalmol 2013; 61(9): 490-496.

23 CATT Research Group, Martin DF, Maguire MG, Ying GS, Grunwald JE, Fine SL et al. Ranibizumab and bevacizumab for neovascular age-related macular degeneration. $N$ Engl J Med 2011; 364(20): 1897-1908. 